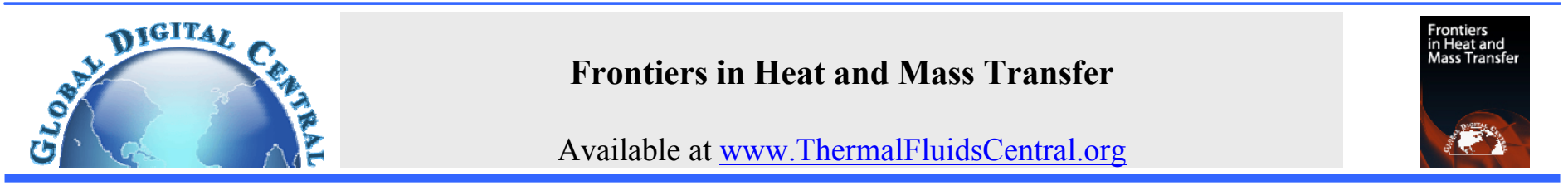

\title{
THE EXPERIMENTAL AND NUMERICAL INVESTIGATION OF THE SOLIDIFICATION OF A POROUS CERAMIC CASTING
}

\author{
Frantisek Kavicka ${ }^{\text {a, }}$ Jana Dobrovska ${ }^{\mathrm{b}}$, Karel Stransky ${ }^{\mathrm{a}}$, Bohumil Sekanina ${ }^{\text {a }}$, Josef Stetina ${ }^{\mathrm{a}}$ \\ ${ }^{a}$ Brno University of Technology, Technicka 2, 61669 Brno, Czech Rep. \\ ${ }^{b}$ VSB, Technical University of Ostrava, 17. listopadu 15, 70833 Ostrava, Czech Rep.
}

\begin{abstract}
Corundo-baddeleyit material (CBM) - EUCOR - is a heat- and wear-resistant material even at extreme temperatures. This article introduces an original numerical model of solidification and cooling of this material in a non-metallic mold. The second, cooperating model of chemical heterogeneity and its application on EUCOR samples prove that the applied method of measuring the chemical heterogeneity provides the detailed quantitative information on the material structure and makes it possible to analyze the solidification process. The verification of both numerical models was conducted on a real cast 350 × 200 x $400 \mathrm{~mm}$ block.
\end{abstract}

Keywords: corundo-baddeleyit material, temperature field, chemical heterogeneity, numerical models

\section{INTRODUCTION}

EUCOR belongs to the not too well known system of the $\mathrm{Al}_{2} \mathrm{O}_{3}-\mathrm{SiO}_{2}$ $\mathrm{ZrO}_{2}$ oxide ceramics. Throughout the world, it is produced only in several plants - in the Czech Republic under the name of EUCOR. This production process entails solely the utilisation of waste material from relined furnaces from glass-manufacturing plants (Fig.1).

The melting of this material is done in electric-arc furnaces lined with material of the same chemical composition. The basic approximate chemical composition of CBM (in weight \%) is $13-17 \% \mathrm{SiO}_{2}, 49$ $52 \% \mathrm{Al}_{2} \mathrm{O}_{3}, 30-33 \% \mathrm{ZrO}_{2}, 0.1 \% \mathrm{TiO}_{2}, 0.2 \mathrm{CaO}, 0.2 \% \mathrm{FeO}$ and $(1.0-$ $2.0 \%$ ) alkaline oxides. Mineralogical, i.e. the phase composition of this ceramic material is given in weight $\%$ as: $48-50 \%$ corundum, $30-$ $32 \%$ baddeleyit and $18-20 \%$ glass phase (Prospectus EUCOR, 2000).

From the foundry property viewpoint, EUCOR has certain characteristics that are similar to the behaviour of cast metal materials, especially steel for castings (Chvorinov, 1954; Ticha et al, 2000). For example, the cooling of EUCOR blocks was monitored and measured with the aim of determining the solidification constant $\mathrm{K}\left[\mathrm{cm} \cdot \mathrm{min}^{-1 / 2}\right]$ according to Chvorinov (Chvorinov, 1954). During the calculation of this constant according to Chvorinov, the release of heat was considered only in the direction perpendicular to the wall of the casting, together with the corresponding calculated modulus of cast blocks $\mathrm{M}=10 \mathrm{~cm}$. This corresponded according to the basic relationship, $M=K \sqrt{ } \tau$ where $\tau$ is the solidification time in minutes, the solidification constant:

- $\mathrm{K}=0.669\left[\mathrm{~cm} \cdot \mathrm{min}^{-1 / 2}\right]$ for a casting in a mixture of sand and water-glass without metal chills, and

- $\mathrm{K}=0.890\left[\mathrm{~cm} \cdot \mathrm{min}^{-1 / 2}\right.$ ] for a casting in a mixture of sand and water-glass with approximately $50 \%$ of metal chills.

The determined solidification constants are close to those of metal castings (Kavicka et al., 2001; Stransky et al., 2001). EUCOR castings can also be risered - to a certain extent in a similar way as casting steel for castings. In order to ensure their correct functioning, it is necessary

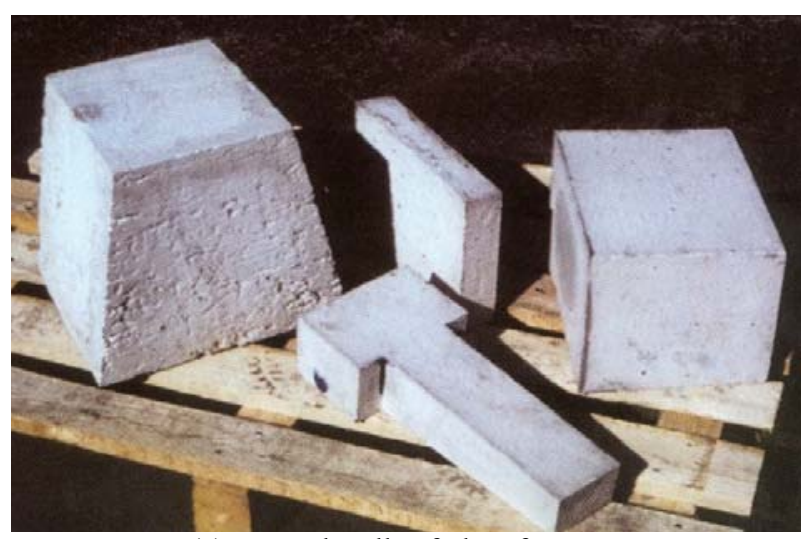

(a) Internal walls of glass furnaces

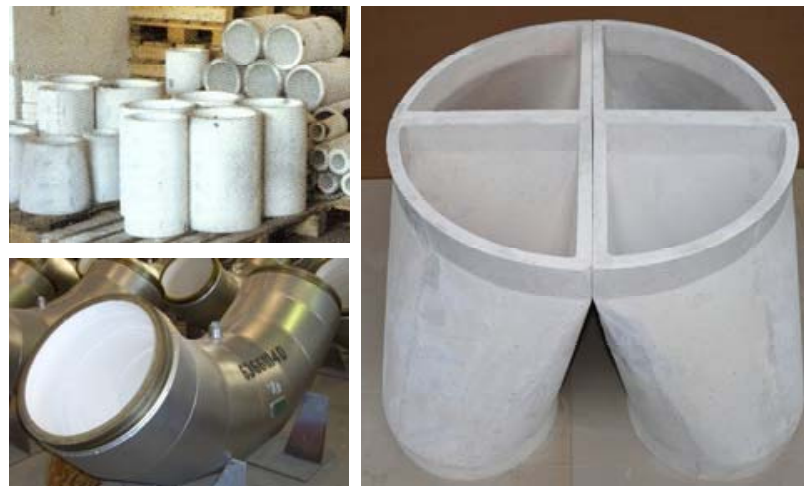

(b) Wear-resistant product

Fig. 1 Production process of EUCOR

\footnotetext{
${ }^{*}$ Corresponding author.Email:kavicka@fme.vutbr.cz
} 
to perforate the crust several times during solidification, for the surface layer of the melt solidifies quickly and prevents the further flow of the melt from the riser to the actual casting. Regarding the high volume contraction during solidification $(6.5 \%)$, it is necessary to select a riser where the ratio of casting-to-riser is $7: 3$, and count with $70 \%$ utilization of melt even when the level (of the riser) is insulated with Sibral and its multiple perforation. With risers that are prone to cracking, it is necessary, within the temperature range from $970{ }^{\circ} \mathrm{C}$ to $560{ }^{\circ} \mathrm{C}$, to ensure cooling at a rate of less than $50{ }^{\circ} \mathrm{C} /$ hour.

The paper introduces a numerical model of the kinetics of the temperature field and a successive numerical model of chemical heterogeneity and their application on cast EUCOR.

\section{THE ASSIGNMENT AND PREPARATION}

The assignment focused on investigating the transient 3D temperature field of a system comprising a casting-and-riser, the mold and ambient, using a numerical model. The dimensions of the casting - the so-called 'stone'-were 400 × 350 × 200 mm (Fig. 2).

The initial temperature of the mold was $20^{\circ} \mathrm{C}$. The pouring temperature of the melt was $1800{ }^{\circ} \mathrm{C}$ which is approximately $300{ }^{\circ} \mathrm{C}$ higher than, for example, the pouring temperature of steel. The temperature of the liquidus was $1775^{\circ} \mathrm{C}$ and the solidus $1765^{\circ} \mathrm{C}$.

The temperature field is symmetrical along the axes, i.e. it is sufficient to investigate the temperature field of one quadrant only. The resultant heat flow through both longitudinal sections is equal to zero. Figure 3 shows the network for the original casting, riser and mold.

The coefficients of heat transfer by radiation and convection in all planes bordering the system into the ambient were defined. Ideal physical contact was presumed between the mold and the casting and between the mold and the riser.
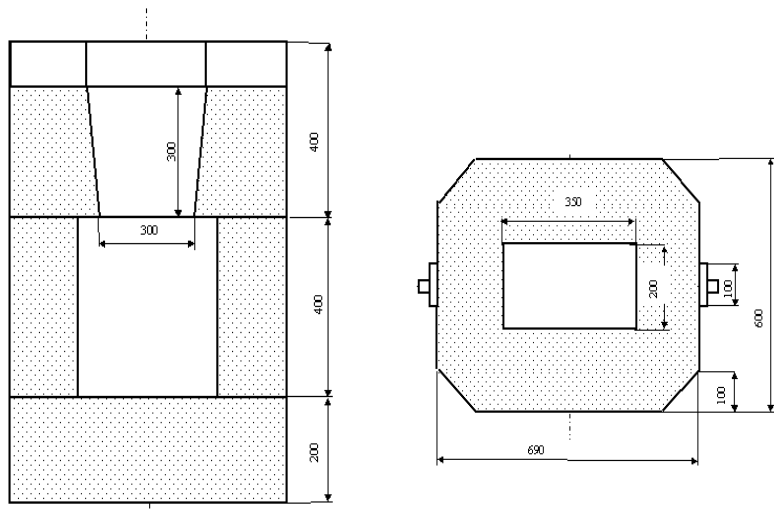

Fig. 2 The casting-riser-mold system

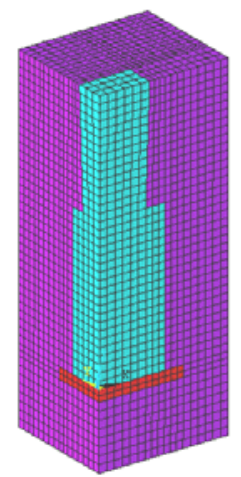

Fig. 3 The 3D network of the system with the original riser

\section{THE NUMERICAL MODEL OF THE TEMPERATURE FIELD}

Solidification - crystallization - and cooling belong to the most important technological processes. They are the cases of 3D (threedimensional) heat and mass transfer. In systems, comprising the casting, the mold and ambient, all three kinds of heat transfer take place. As these problems cannot be solved analytically - even with the secondorder partial differential Fourier equation (1) (where the mass transfer is neglected and conduction is considered as the most important of the three kinds of heat transfer) - it is necessary to engage numerical methods. The equation (1) describes the transient temperature field in a mold. Its properties $k, c$, and $\rho$ are considered as constant.

$$
\begin{aligned}
& \frac{d T}{d \tau}=\frac{k}{\rho . c}\left(\frac{\partial^{2} T}{\partial x^{2}}+\frac{\partial^{2} T}{\partial^{2}}+\frac{\partial^{2} T}{\partial^{2}}\right)+\frac{Q_{\text {SOURCE }}}{\rho . c} \\
& a=\frac{k}{\rho . c} \\
& \frac{d T}{d \tau}=a \cdot \Delta T+\frac{Q_{\text {SOURCE }}}{\rho . c} \\
& \frac{d T}{d \tau}=a . \nabla^{2} T+\frac{Q_{\text {SOURCE }}}{\rho . c}
\end{aligned}
$$

The Fourier equation for a casting must be adapted in such a way that it would describe the temperature field of a casting in its all three phases: in the melt, in the mushy zone and in the solid phase. Here, it is necessary to introduce the specific volume enthalpy $h_{v}=c . \rho . T$, which is temperature dependent. The thermodynamic enthalpy function includes also latent heat of the phase or structural changes. The equation then takes the following form:

The specific heat capacity $c$, density $\rho$ and heat conductivity $k$ are also temperature functions. The dependence of the heat capacity on temperature is shown in Fig. 4, heat conductivity in Fig. 5 and density in Fig. 6. The enthalpy function must be known for EUCOR (Fig.7).

The explicit difference method had been chosen for the solution of both equations because it enableds the application of the most convenient numerical simulation method of the latent heat release of the phase and structural changes using the thermodynamic enthalpy function. The program also considers the non-linearity of the task. The dependence of the EUCOR thermo-physical properties on the temperature, and the dependence of the heat-transfer coefficients (on all boundaries of the system) on the surface temperature - of the casting and the mold.

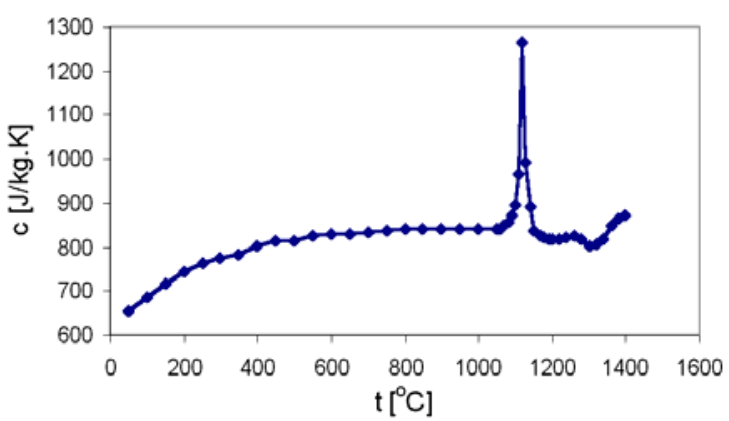

Fig. 4 The heat capacity-temperature dependence 


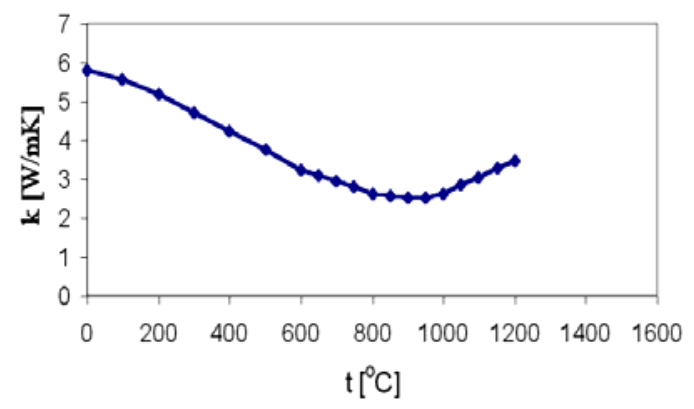

Fig. 5 The heat conductivity-temperature dependence

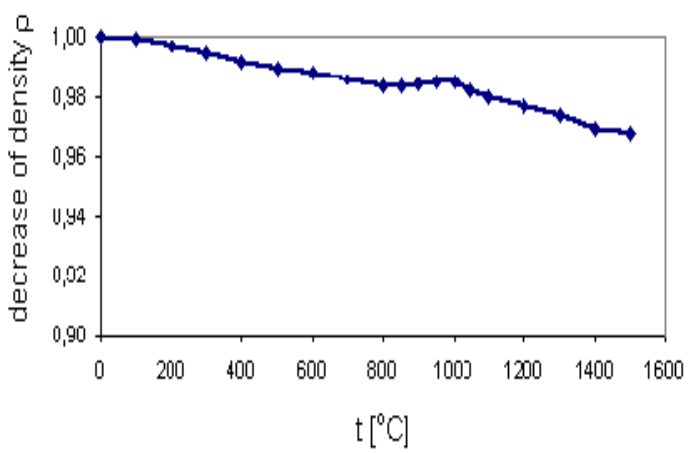

Fig. 6 The density-temperature dependence

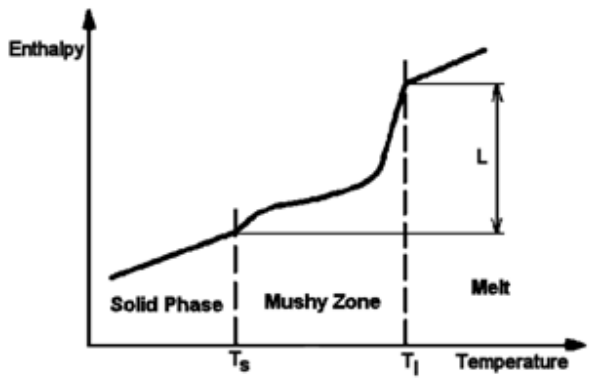

Fig. 7 The enthalpy function

Software ANSYS integrates an original mesh generator (i.e. the pre-processing) as well as the post-processing (i.e. the graphic output) of the results and a user can thus change the pouring parameters, the dimensions of the casting-mold system and the dimensions of the elementary mesh volume before the actual calculation. The number of nodal points can be anywhere within the range from $10^{6}$ to $10^{7}-$ this density makes it possible to cover castings of more complex shapes. The density also makes it possible to approximate the linear distribution of temperatures between individual points of the 3D mesh and even within time intervals.

\section{THE EXPERIMENT}

The numerical model of the temperature field of the casting was confronted with experimental measurements and corrected. The temperatures were measured in the actual casting and also in the mold. Special tungsten-rhenium thermocouples had to be used for the measurement within the actual casting, in order to withstand the high pouring temperature. The measurement points are shown in Fig. 8 (T1T11). Figure 9 shows the inside of the unassembled experimental mold. Three GRANT measurement stations were used for the recording of temperatures throughout the process (Fig. 10).

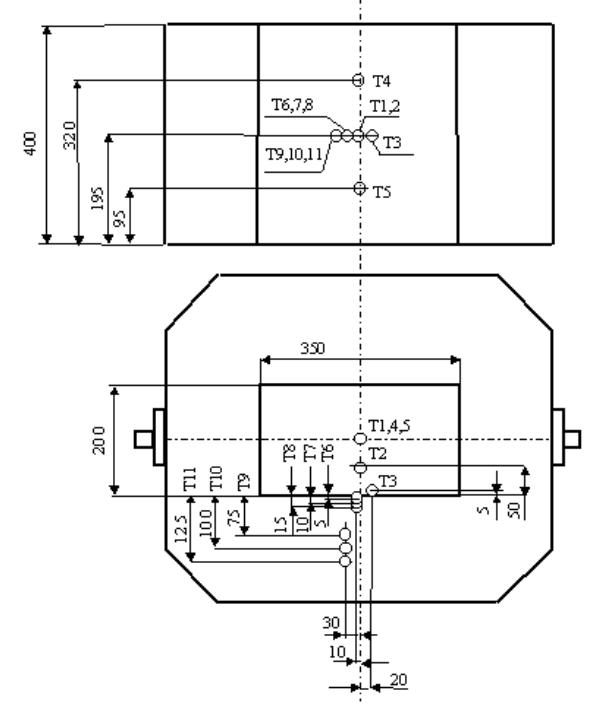

Fig. 8 Measurement points

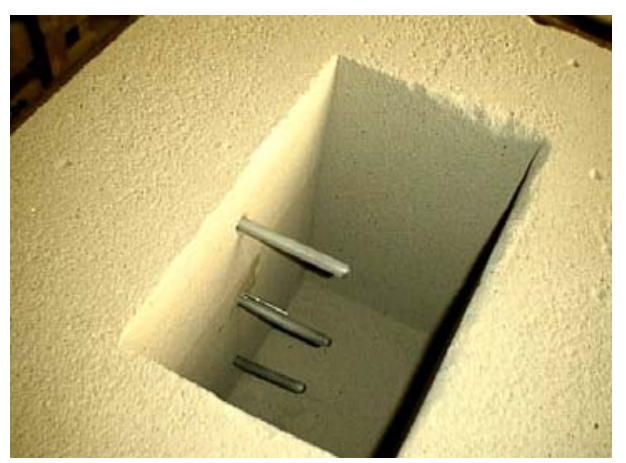

Fig. 9 The inside of the unassembled experimental mold

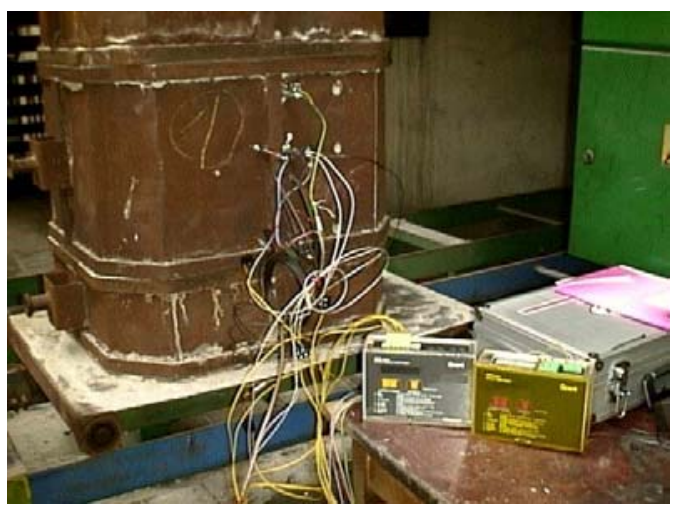

Fig. 10 GRANT measurement stations

\section{MEASUREMENT AND COMPUTATIONAL RESULTS (ORIGINAL RISER)}

The results attained from the numerical analysis of the temperature field of a solidifying casting and the heating of the mold represent only one quadrant of the system in question. Figure 11 shows the 3D temperature field of the casting with the original riser and the mold at four times after pouring.

The results attained from the numerical analysis of the temperature field of a solidifying casting and the heating of the mold represent only one quadrant of the system in question. Figure 11 shows the 3D 
temperature field of the casting with the original riser and the mold at four times after pouring.

An interesting place for monitoring is the riser-mold interface. Once this point solidifies the riser can no longer affect the process inside the casting. Of the four charts in Fig. 12, only the first one shows the temperature field at a moment when the original riser is still functional ( $3600 \mathrm{~s})$. The measured and computed temperature history of, for example, point T5 in the casting and T6 in the mold is in Fig. 13. In both graphs the blue line represents the measured and the red line represents the computed values. The comparison is satisfactory.

Using the original riser, directed solidification (which is the primary condition for a "healthy" casting) is not achieved because the riser is 'frozen' (i.e. the 'refilling' of the casting from the riser is cut off) at $5200 \mathrm{~s}$ after pouring (Fig. 14).
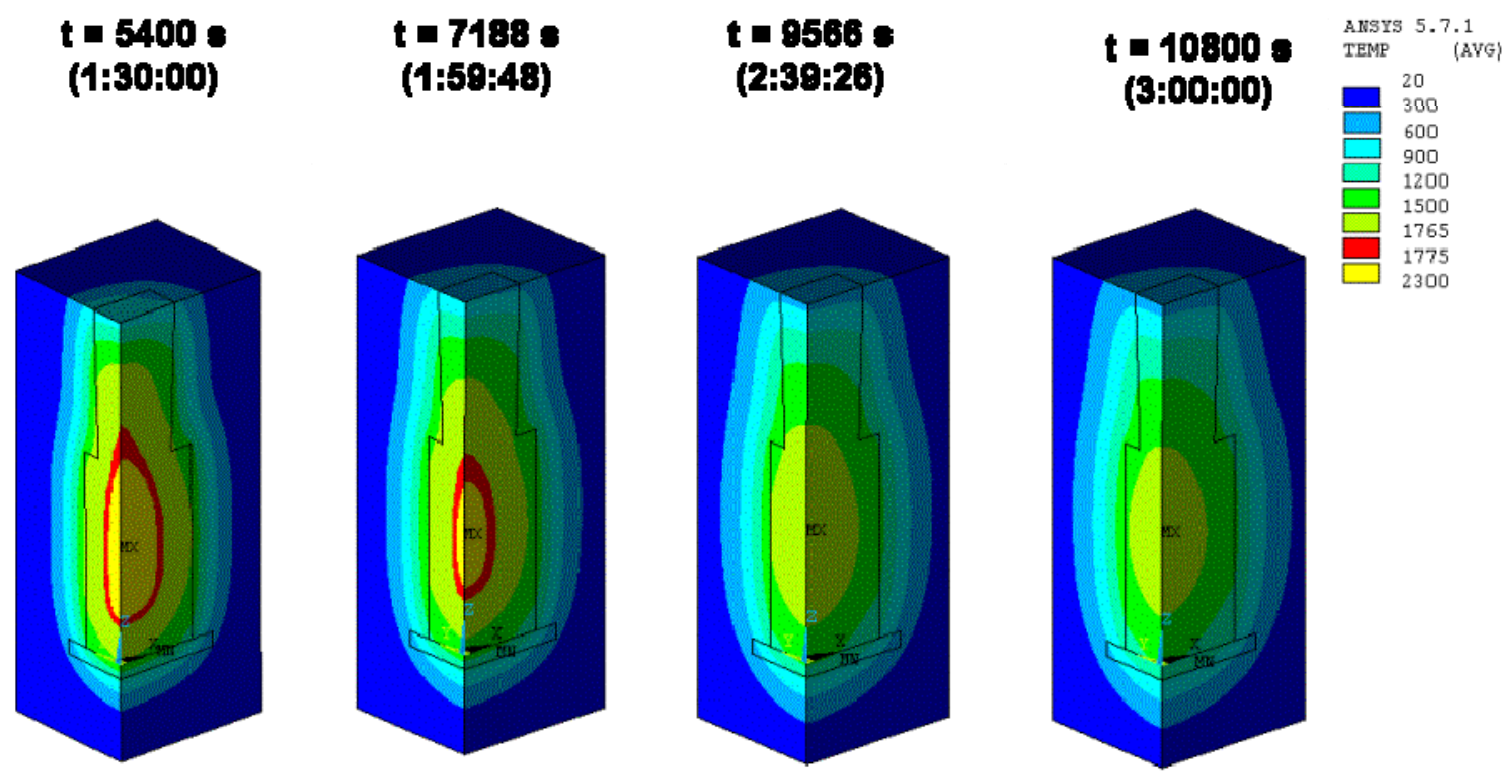

Fig. 11 The 3D temperature field of one quadrant of the casting with riser-mold

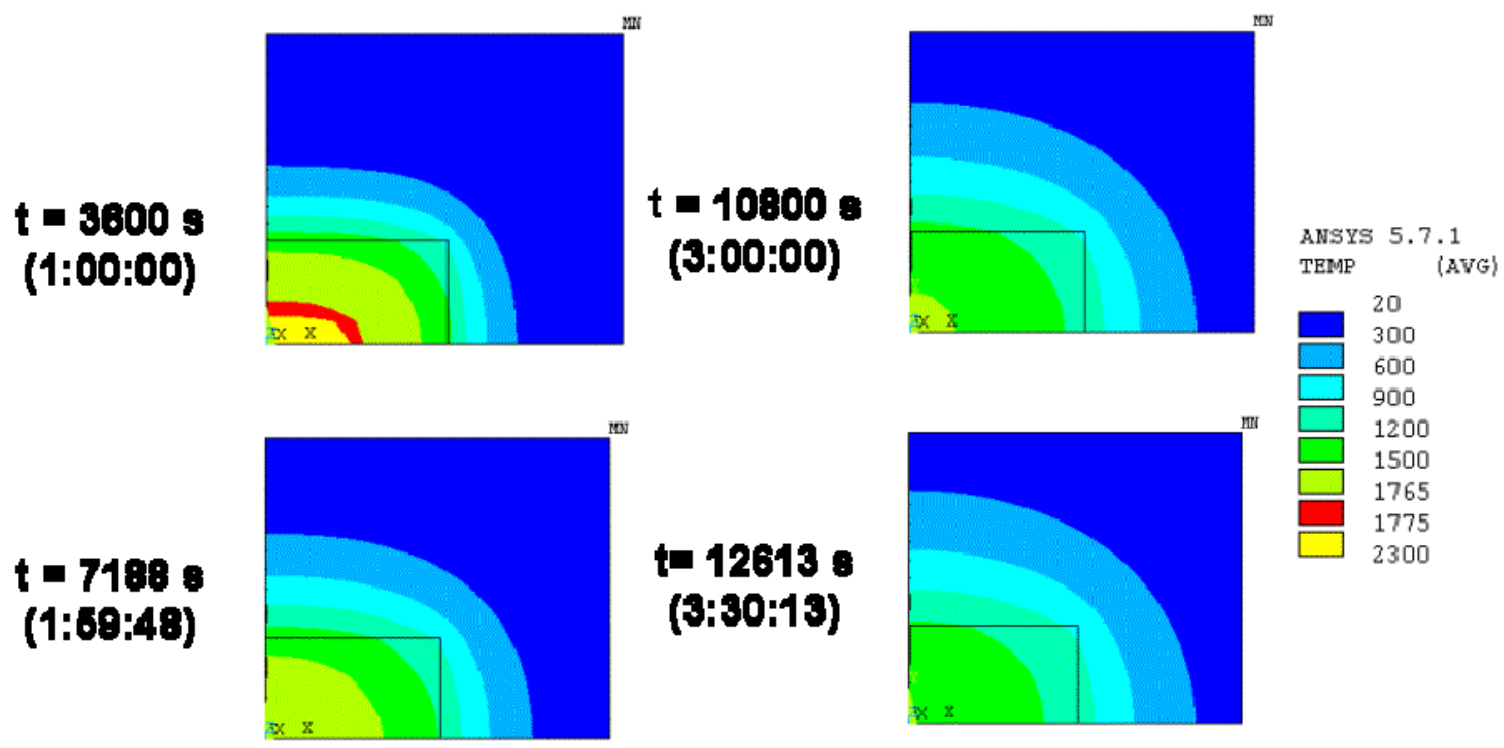

Fig. 12 The 2D temperature field on the riser-mold and riser-casting interface 


\section{T5 - Casting}

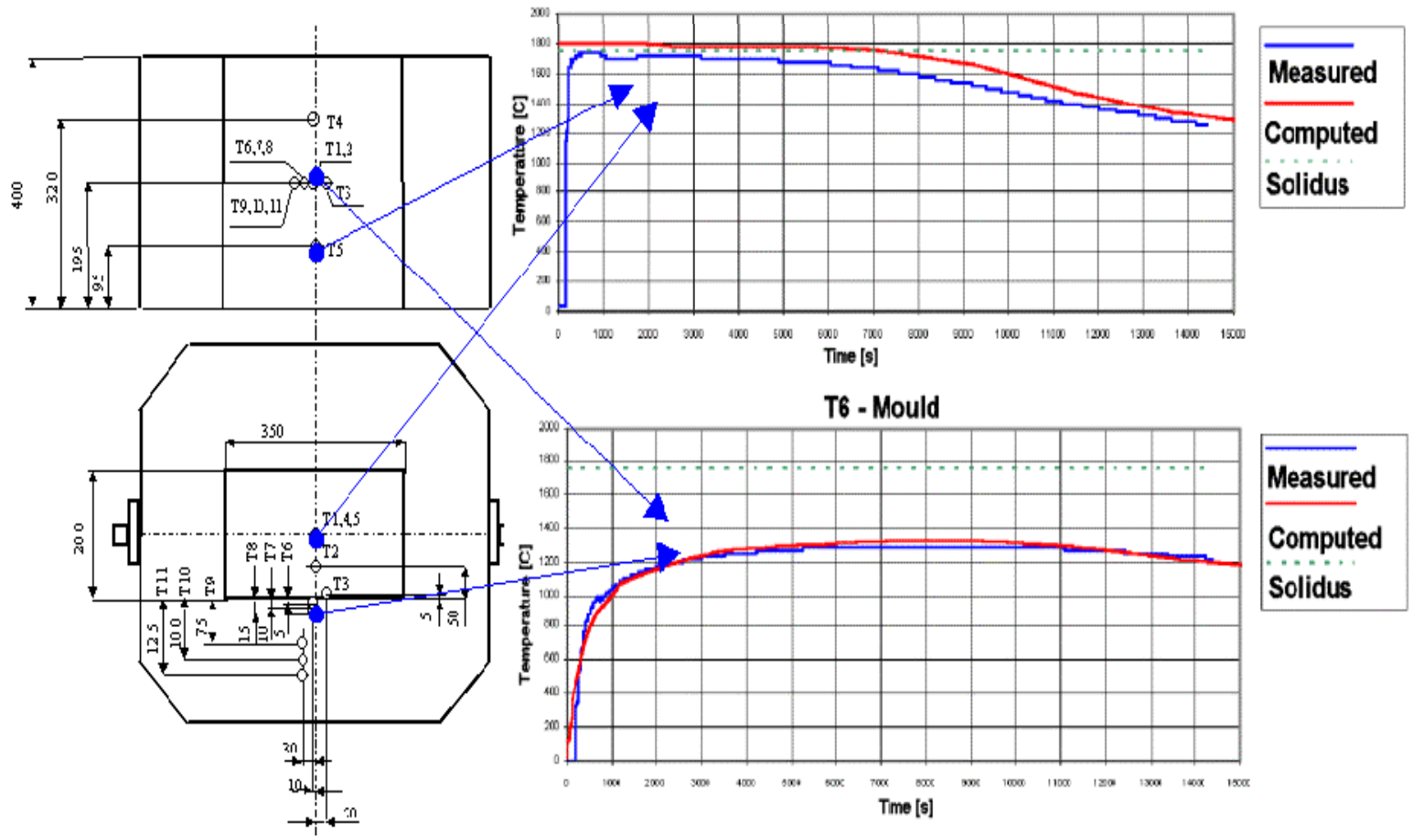

Fig. 13 The measurement points and the measured and computed temperature history of the points T5 and T6

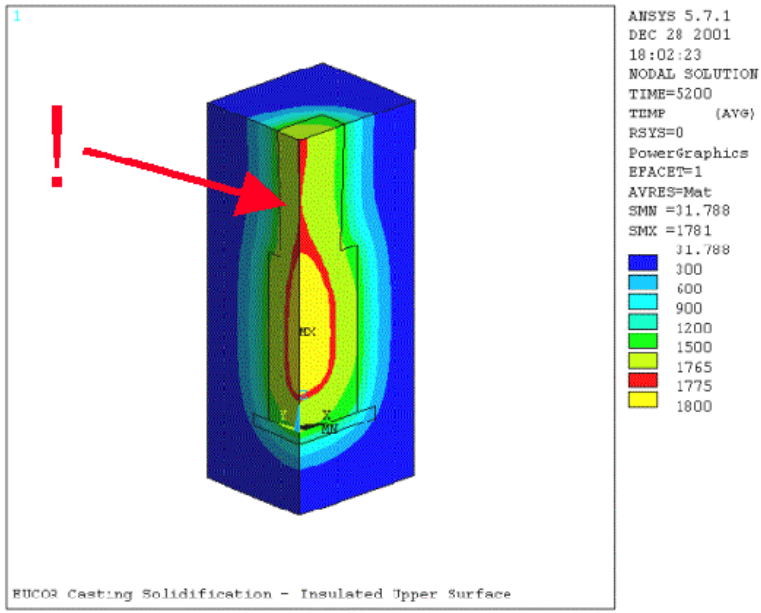

Fig. 14 The temperature field of the system comprising the casting, the original riser and mold at 5200s

\section{OPTIMIZATION OF THE RISER}

The new shape of the riser was selected according to the latest findings. After several modifications, the application with an optimized riser ensured directed solidification. The network of the system with the new riser is in Fig. 15. Figures 16-18 compare the temperature fields of the casting and riser inside the mold at 6 points in time-from the pouring into the mold to the total solidification. The left figure of each pair represents the original riser and the right one represents the optimized riser. The casting with the new riser has directed solidification - the casting is still being refilled from the riser.

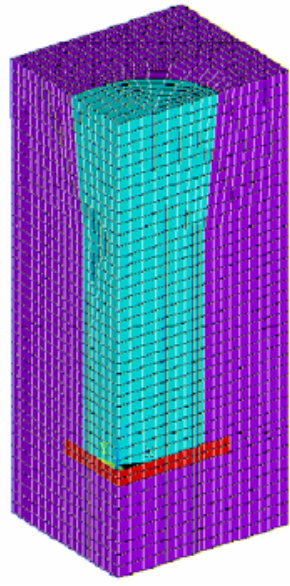

Fig. 15 The 3D network of the system with the new riser

\section{THE MODEL OF THE CHEMICAL HETEROGENEITY AND ITS APPLICATION}

The concentration distribution of individual oxides, making up the composition of the ceramic material EUCOR, was determined using an original method (Dobrovska at al., 1998) and applied in the process of measuring the macro- and micro-heterogeneity of elements within ferrous alloys. This method was initially modified with respect to the differences occurring during solidification of the ceramic material, when compared to ferrous alloys. 


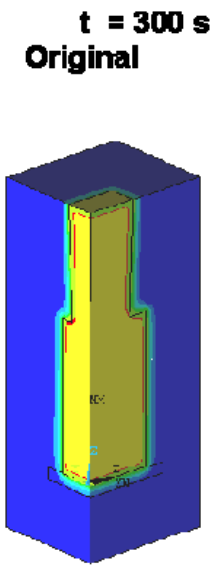

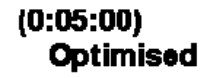

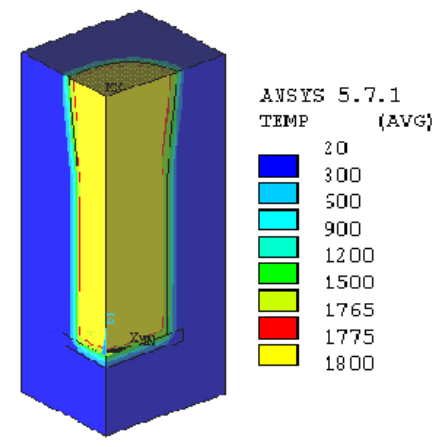

\section{Original}

$t=1800 \mathrm{~s} \quad(0: 30: 00)$

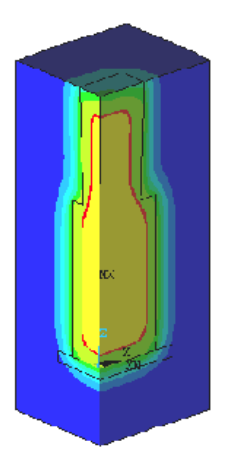

\section{Optimised}

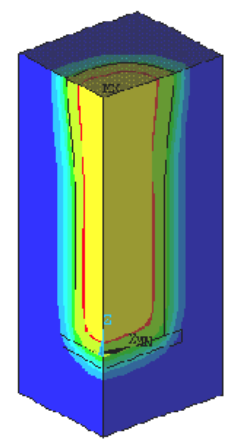

Fig. 16 The temperature fields before and after optimization ( $300 \mathrm{~s}$ and $1800 \mathrm{~s}$ after pouring)
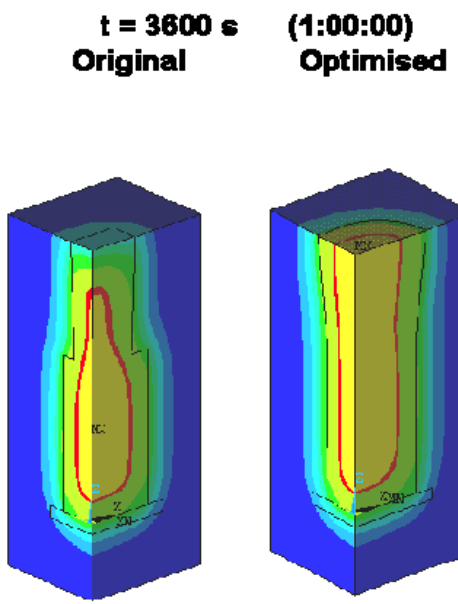

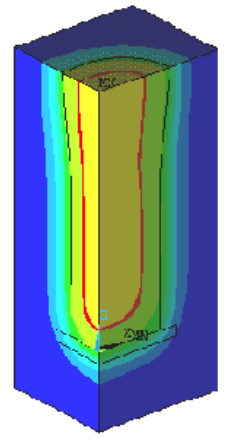

$\mathbf{t}=\mathbf{7 1 8 8 \mathrm { s }}$ Original

\section{The Freezhg}

of the RIser

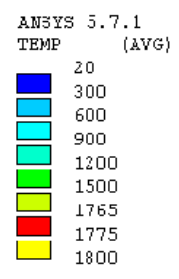

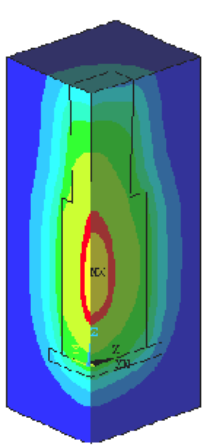

(1:59:48)

Optimised

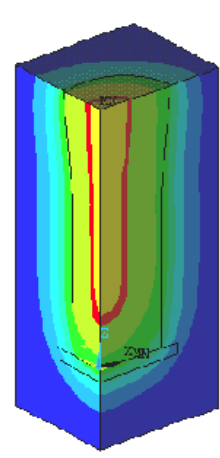

Fig. 17 The temperature fields before and after optimization ( $3600 \mathrm{~s}$ and $7188 \mathrm{~s}$ after pouring)

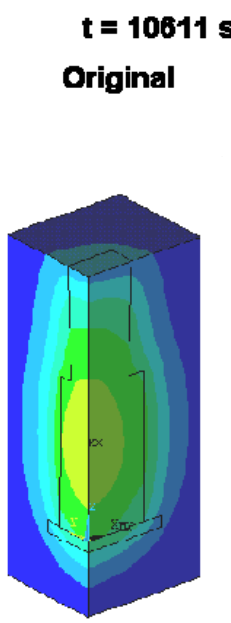

(2:56:51)

Optimised

Solldincation

In the Casting

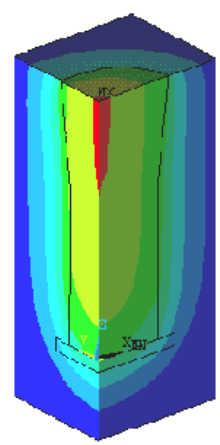

$t=12127 \mathrm{~s}$

Original

(3:22:07)

Optimised

Complete

Solidification
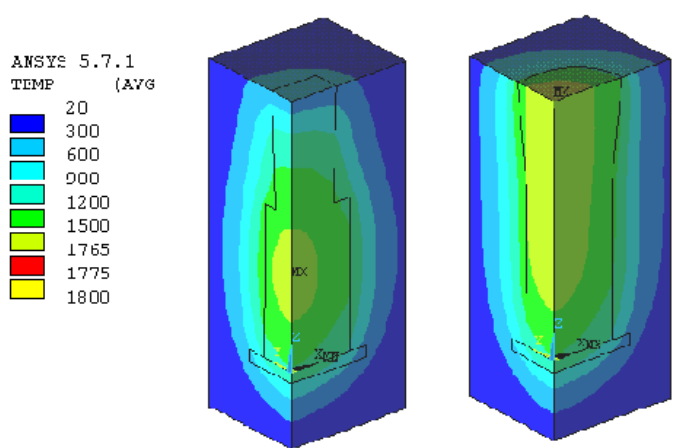

Fig. 18 The temperature fields before and after optimization (10611 s and $12127 \mathrm{~s}$ after pouring)

It was presumed that within EUCOR, the elements had been already distributed, together with oxygen, at the stoichiometirc ratio (i.e. the chemical equation), which characterized the resulting composition of the oxides of individual elements after solidification.

The preconditions for the application of the model of chemical heterogeneity on the EUCOR material are as follows:
If the analytically expressed distribution of micro-heterogeneity of the oxides of the ceramic material is available, if their effective distribution coefficient is known, and if it is assumed that it is possible to describe the solidification of the ceramic material via analogical models as with the solidification of metal alloys, then it is possible to conduct the experiment on the mutual combination of the calculation of 
the temperature field of a solidifying ceramic casting with the model describing the chemical heterogeneity of the oxides.

If the Brody-Flemings model (Brody and Flemings, 1966) is applied for the description of the segregation of oxides of the solidifying ceramic material and if an analogy with metal alloys is assumed, then it is possible to express the relationship between the heterogeneity index $I_{\text {het }}$ of the relevant oxide, its effective distribution coefficient $k_{e f}$ and the dimensionless parameter $\alpha$ using the equation

$\frac{\ln \left(2 \alpha k_{e f}\right)}{1-2 \alpha k_{e f}}=\frac{\ln \frac{\left(1+n I_{\text {het }}^{(m)}\right)}{k_{e f}}}{\left(k_{e f}-1\right)}$

the right-hand side of which $\left.\left\{\ln \left(1+n I_{h e t}{ }^{(m)}\right) / k_{e f}\right\}\right\} /\left(k_{e f}-1\right)$, based on the measurement of micro-heterogeneity, is already known and through whose solution it is possible to determine the parameter $\alpha$, which is also on the right-hand side of the equation in $2 \alpha k_{e f}=X$. The quantity $n$ has a statistical nature and expresses what percentage of the measured values could be found within the interval $\mathrm{x}_{\mathrm{s}} \pm n \mathrm{~s}_{\mathrm{x}}$ (where $\mathrm{x}_{\mathrm{s}}$ is the arithmetic mean and $s_{x}$ is the standard deviation of the set of values of the measured quantity). If $n=2$, then $95 \%$ of all measured values can be found within this interval.

If the dimensionless parameter $\alpha$ is known for each oxide, then a key to the clarification of the relationship exists between the local EUCOR solidification time $\theta$, the diffusion coefficient $D$ of the relevant oxide within the solidifying phase and the structure parameter $L$, which characterizes the distances between individual dendrites (in steels) or cells (in ceramics). The equation of the dimensionless parameter $\alpha$ is

$\alpha=\frac{D \theta}{L^{2}}$

It is possible to take the dimension of a structure cell as the structure parameter for the EUCOR material.

The verification of the possibility of combining both methods was conducted on samples taken from the EUCOR blocks - from the edge (sample B) - and from the centre underneath the riser (sample C).

Both the measured and the computed parameters of chemical micro-heterogeneity and the computed parameters of the local solidification time $\theta$ (according to the temperature-field model) were calculated. The local solidification time of the sample $\mathrm{B}$ was $\theta_{B}=112.18 \mathrm{~s}$ and of the sample $\mathrm{C}$ was $\theta_{C}=283.30 \mathrm{~s}$. The computed values of parameter $\alpha$ and the local solidification time $\theta$ determine, via their ratio, the quotient of the diffusion coefficient $D$ and the square of the structure parameter $L$, which means that the following relation applies:

$\frac{\alpha}{\theta}=\frac{D}{L^{2}} \quad\left[s^{-1}\right]$

The calculated values of relation (7) for oxides of the samples B and $\mathrm{C}$ are arranged in Table 1 together with the parameters $\alpha$ :

It comes as a surprise that the values of the parameter $\alpha / \theta=D / L^{2}$ of the oxides of elements- $\mathrm{Na}, \mathrm{Al}, \mathrm{Si}, \mathrm{K}, \mathrm{Ca}, \mathrm{Ti}$, and $\mathrm{Fe}$ differed by as much as an order from the value of the same parameter of the oxide of zirconium and hafnium. This could be explained by the fact that zirconium contains hafnium as an additive and, therefore, they segregate together and the forming oxides of zirconium and hafnium show the highest melting temperatures. From the melt, both oxides segregated first, already in their solid states. Further redistribution of the oxides of both elements ran on the interface of the remaining melt and the successive segregation of other oxides only to a very limited extent. It was therefore possible to count on the fact that the real diffusion coefficients of zirconium and hafnium in the successively forming crystallites were very small (i.e. $D_{\mathrm{Zr}} \rightarrow 0$ and $D_{\mathrm{Hf}} \rightarrow 0$ ). On the other hand, the very close values of the parameters $\alpha / \theta=D / L^{2}$ of the remaining seven analyzed oxides

$$
\frac{D}{L_{B}^{2}}=(6.51 \pm 0.25) \cdot 10^{-4}\left[s^{-1}\right], \quad \frac{D}{L_{C}^{2}}=(2.45 \pm 0.12) \cdot 10^{-4}\left[s^{-1}\right]
$$

indicated that the redistribution of these oxides between the melt and the solid state ran in a way, similar to that within metal alloys, namely steels.

Table 1. Calculated values of the equation (7)

\begin{tabular}{|l|l|l|l|l|}
\hline Oxide & $\begin{array}{l}\text { Sample B: } \\
\boldsymbol{\alpha}\end{array}$ & $\begin{array}{l}\alpha / \theta_{\mathrm{B}} \cdot 10^{4} \\
{[1 / \mathrm{s}]}\end{array}$ & $\begin{array}{l}\text { Sample C: } \\
\boldsymbol{\alpha}\end{array}$ & $\begin{array}{l}\alpha / \theta_{\mathrm{C}} \cdot 10^{4} \\
{[1 / \mathrm{s}]}\end{array}$ \\
\hline \hline $\mathrm{Na}_{2} \mathrm{O}$ & 0.0732 & 6.53 & 0.0691 & 2.44 \\
\hline $\mathrm{Al}_{2} \mathrm{O}_{3}$ & 0.0674 & 6.01 & 0.0662 & 2.34 \\
\hline $\mathrm{SiO}_{2}$ & 0.0741 & 6.61 & 0.0663 & 2.34 \\
\hline $\mathrm{ZrO}_{2}$ & 0.00035 & 0.0312 & 0.00008 & 0.0028 \\
\hline $\mathrm{K}_{2} \mathrm{O}$ & 0.0721 & 6.43 & 0.0665 & 2.35 \\
\hline $\mathrm{CaO}$ & 0.075 & 6.69 & 0.0703 & 2.48 \\
\hline $\mathrm{TiO}_{2}$ & 0.0759 & 6.77 & 0.0757 & 2.67 \\
\hline $\mathrm{Fe}_{2} \mathrm{O}_{3}$ & 0.0732 & 6.53 & 0.0711 & 2.51 \\
\hline $\mathrm{HfO}_{2}$ & 0.0165 & 1.47 & 0.00017 & 0.006 \\
\hline
\end{tabular}

It would be possible to count - in the first approximation - the diffusion coefficients of the oxides in the slag having the temperatures of $1765^{\circ} \mathrm{C}$ (solidus) and $1775^{\circ} \mathrm{C}$ (liquidus), the average value of $(2.07 \pm 0.11) \times 10^{-6} \mathrm{~cm}^{2} / \mathrm{s}$ (the data referred to the diffusion of aluminum in the slag of a composition of $39 \% \mathrm{CaO}-20 \% \mathrm{Al}_{2} \mathrm{O}_{3}-41 \% \mathrm{SiO}_{2}$ ). For these cases, and using Eq. (5), it was possible to get the magnitude of the structure parameters that governed the chemical heterogeneity of the values:

$$
\begin{aligned}
& L_{B}=\sqrt{\frac{2.07 \times 10^{-6}}{6.51 \times 10^{-4}}}=0.05639[\mathrm{~cm}] \\
& L_{B}=\sqrt{\frac{2.07 \times 10^{-6}}{2.45 \times 10^{-4}}}=0.09192[\mathrm{~cm}]
\end{aligned}
$$

which corresponded to $564 \mu \mathrm{m}$ in the sample B (which was taken from the edge of the casting block) and $919 \mu \mathrm{m}$ in the sample $\mathrm{C}$ (which was taken from underneath the riser of the same casting block).

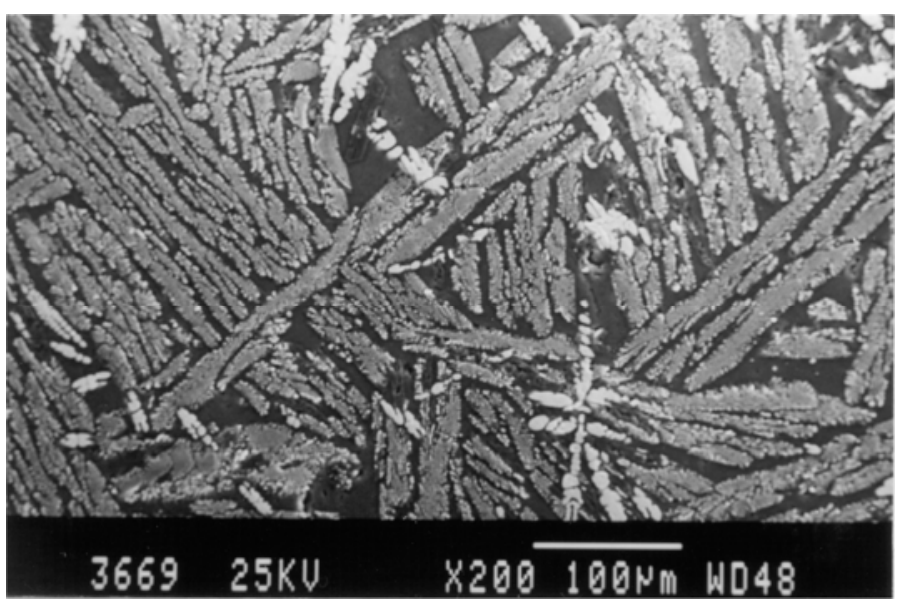

Fig. 19 The structure of the sample $B\left(L_{B}=564 \mu \mathrm{m}\right)$ 


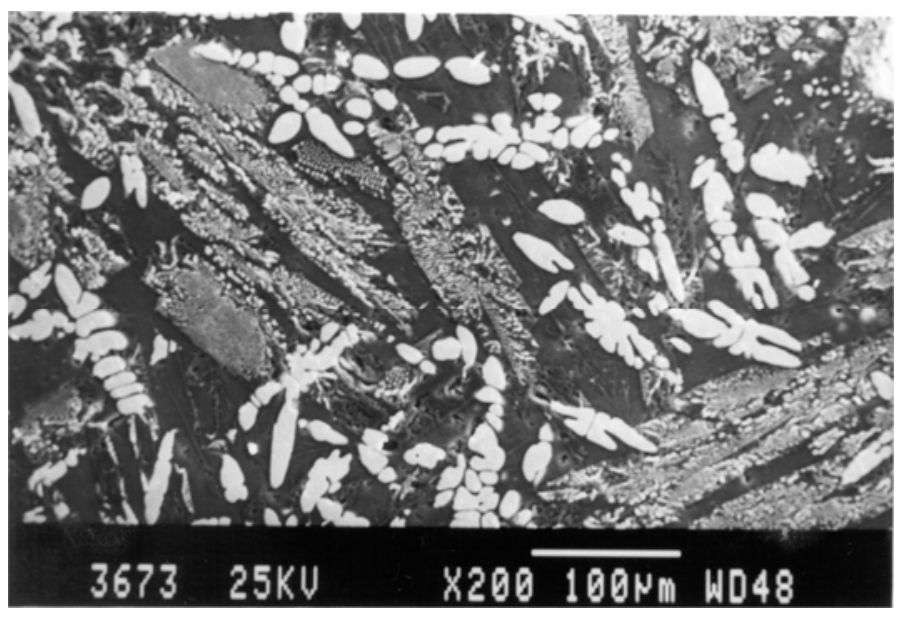

Fig. 20 The structure of the sample $\mathrm{C}\left(L_{\mathrm{C}}=919 \mu \mathrm{m}\right)$

The comparison of the micro-structures of the analyses samples B and $\mathrm{C}$ (Fig. 19 and 20) has clearly shown that the sample B microstructure $\left(L_{\mathrm{B}}\right)$ was significantly finer than the micro-structure of the sample $\mathrm{C}\left(L_{\mathrm{C}}\right)$, which semi-quantitatively corresponded to the qualified estimate of the structure parameters $L$, conducted on the basis of calculations using the data obtained from both models. Other samples from similar parts of the casting block - the edge of the casting block, sample B2 (Fig. 21) and underneath the riser, sample C2 (Fig. 22) confirm these diferences of micro-structure.

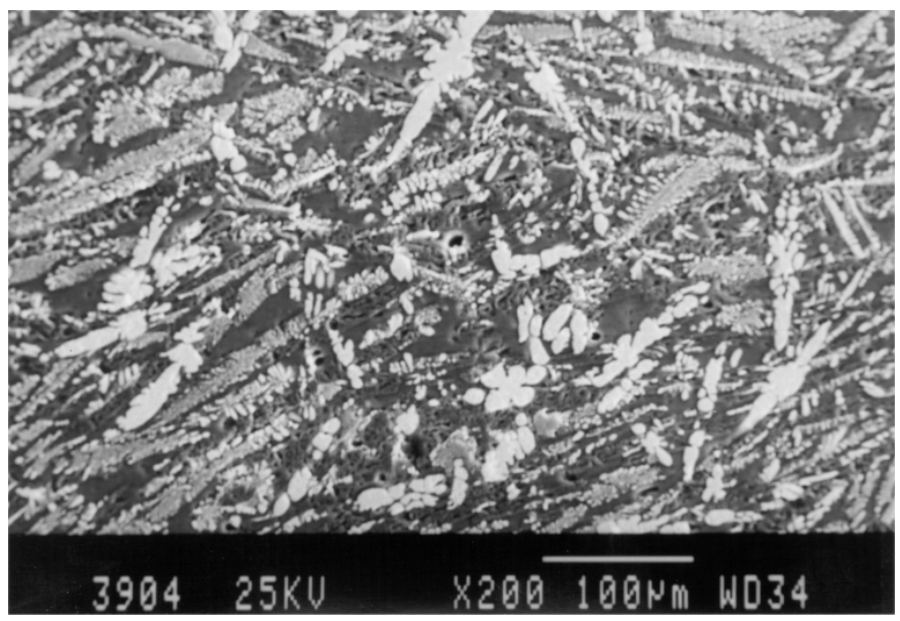

Fig. 21 The structure of the sample B2

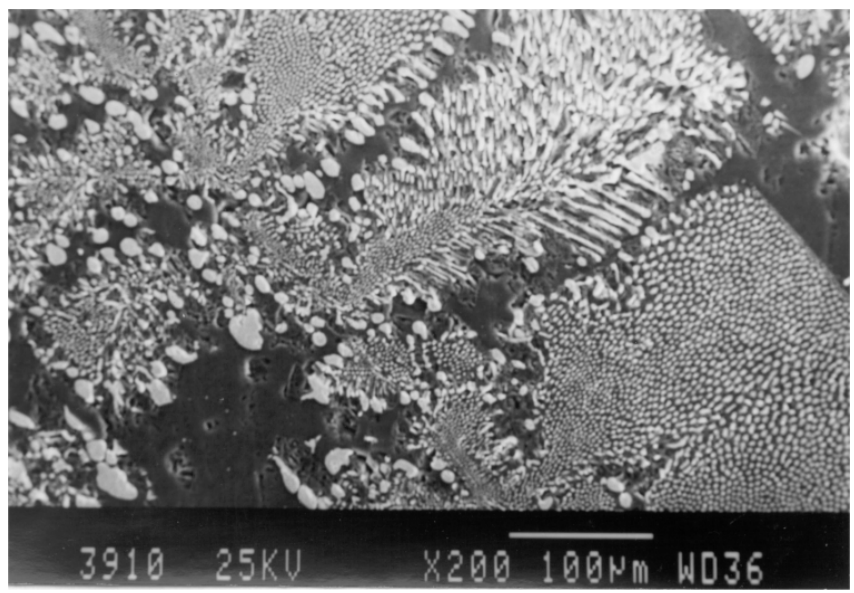

Fig. 22 The structure of the sample $\mathrm{C} 2$

\section{CONSEQUENCES OF THE CHEMICAL HETEROGENEITY MODEL}

The sample B structure in Fig. 19 characterizes higher cooling velocity of the EUCOR material from the solidus temperature, when compared with the structure $\mathrm{C}$ in Fig. 20. These two figures show that the higher diameter of the structure parameter $L$ corresponds to the lower cooling velocity of the same material. Both structure parameters, $L_{\mathrm{B}}$ and $L_{\mathrm{C}}$, were calculated using the combination of two models (the numerical model of the temperature field and the model of the chemical heterogeneity). The numerical model of the temperature field of the casting block solidification provides the information about the local solidification time at any point of the casting, it also means at any critical point of the casting, which has the tendency to crack or to fracture. The model of the chemical heterogeneity creates the chance to estimate the structures parameters in this critical point of castings.

After fracture mechanics, it was possible, in the first approximation, to write the equation

$K_{I C} \geq \sigma_{B} \sqrt{\pi L_{B}}=\sigma_{C} \sqrt{\pi L_{C}}$

where $K_{I C}$ is the fracture toughness [MPa.m $\left.{ }^{1 / 2}\right], \sigma_{B}, \sigma_{C}$ are the strains on the structure defects' tips [MPa] and $L_{B}, L_{C}$ are the diameters the structure parameters (cells) in the samples B and $C[\mathrm{~m}]$. The occurrence of primary technological defects on the casting grains is highly probable (the micro-shrinkage porosity, micro-shrinkage cavity, and so on). The Equation 8 implies the following

$\left(\frac{\sigma_{B}}{\sigma_{C}}\right)^{2}=\frac{L_{C}}{L_{B}}=\frac{919.2}{563.9}=1.63$

It means that the relation between the structure parameters $L_{C}$ and $L_{B}$ makes (gives) the relation between of quarter of $\sigma_{B}$ and the $\sigma_{C}$ strain on the tips of potential structure defects of the samples B and C. At the same fracture toughness, the strain on the sample B can be 1.27 times higher, when compared with the strain on the sample $\mathrm{C}$.

\section{CONCLUSIONS}

The investigation of the temperature field had two goals: The directed solidification as the primary condition for a healthy casting and the optimization of the casting technology, together with the preservation of optimal utility properties of the product.

The achievement of these two goals depended on the ability to analyze and, successively, to control the effect of the main factors which characterize the solidification process or accompany it.

The results of the investigation of the quantities should reveal the causes of heterogeneities in castings with respect to the phase and structural changes. It should also focused on the thermo-kinetics of the creation of shrinkage porosities and cavities and on the prediction of their creation and, therefore, on the controlling the optimization of the shape and sizes of the risers, the method of insulation, the treatment of the level, etc.

This paper discusses also the numerical model of the transient temperature field and the numerical model of the chemical heterogeneity, their application and combination. The combination of both models makes it possible to estimate the structure parameter, which expresses the size of the crystallites of the resultant material structure.

The combination of both models creates a tool for the estimation of the tendency to the cracks and fractures in a critical points of the casting from EUCOR material. 


\section{ACKNOWLEDGMENTS}

This analysis was conducted using a program devised within the framework of the GA CR projects No. 106/08/0606, 106/09/0940 and $107 / 11 / 1566$

\section{NOMENCLATURE}

a

$\mathrm{B}, \mathrm{C}$

$c$

$D$

$h_{v}$

$I_{\text {het }}^{(m)}$

$K$

$K_{I C}$

$k$

$k_{e f}$

$L$

\section{$M$}

$n$

$Q_{\text {SOURCE }}$

$s_{x}$

$T$

$x, y, z$

$x_{s}$ temperature conductivity $\left(\mathrm{m}^{2} \mathrm{~s}^{-1}\right)$

description of samples (-)

specific heat capacity $\left(\mathrm{J} \cdot \mathrm{kg}^{-1} \cdot \mathrm{K}^{-1}\right)$

diffusion coefficient of oxide in solid state $\left(\mathrm{cm}^{2} / \mathrm{s}\right)$

specific volume enthalpy $\left(\mathrm{J}_{\mathrm{m}}^{-3}\right)$

measured value of the oxide heterogeneity index (-)

solidification constant $\left(\mathrm{cm} \cdot \mathrm{min}^{-1 / 2}\right)$

fracture toughness $\left(\mathrm{MPa} \cdot \mathrm{m}^{1 / 2)}\right.$

heat conductivity $\left(\mathrm{W} \cdot \mathrm{m}^{-1} \cdot \mathrm{K}^{-1}\right)$

effective distribution coefficient of the volume

element between the solid and liquid states (-)

size (coarseness) of the oxide particles proportional to the distance between dendrites (the structure parameter) $(\mathrm{cm})$

modulus of cast blocks (cm)

statistical multiplication parameter (-)

heat flow from internal source (W. $\mathrm{m}^{-3}$ )

standard deviation of oxide concentration (wt. \%)

Temperature (K)

axes in given directions (-)

arithmetical mean of the oxide concentration (wt. \%)

Greek Symbols

$\alpha=D \theta / L^{2}$

$\theta$

$\rho$
Fourier's criterion for the mass transfer (-)

local solidification time (s)
Density $\left(\mathrm{kg} \cdot \mathrm{m}^{-3}\right)$ $\sigma$

$\tau$

$\Delta$

$\nabla$ strain on the structure defects' tips (MPa)

Time (s)

Laplace operator (-)

nabla operator $(-)$

\section{REFERENCES}

Brody, H.D., and Flemings, M.C., 1966.Trans. AIME, vol. 236, pp. 615-624

Chvorinov, N., 1954. Crystallization and heterogeneity of steels. NCSAV, Prague, Czech Republic.

Dobrovska, J., Dobrovska, V., Rek, A., and Stransky, K., 1998. "Possible ways of prediction of the distribution curves of dendritic segregation of alloying elements in steels". Scripta Materialia, vol. 18, No. 10, pp. 1583-1598.

Kavicka, F., Buchal, A., Z. Buzek., Dobrovska, J., Dobrovska, V., and Stransky, K., 2001. " Castings from corundo-baddeleyit ceramics - their properties and utilization for wear resistant materials, piping, etc". Slevarenstvi 49, No. 9, p. 524-529.

Prospectus EUCOR, 2000. "A heat and wear resistant corundobaddeleyit material”. EUTIT, s. r. o., Stara Voda 196, 353 Marianske Lazne, Czech Republic.

Stransky, K., Bazan, Z., Buzek, Z., Dobrovska, J., and Kavicka, F., 2001. "Heat and wear resistant corundo-baddeleyit ceramics, its properties and utilization". Proceedings of the conference Foundry Ceramics, Roznov pod Radhostem, Czech Republic April, p. 39-45.

Ticha, J., Spousta, V., and Motycka, P., 2000. "Heat and volume relationships during the casting and solidification of the corundobaddeleyit material P- EUCOR". Proceedings of the international metallurgical symposium Metal 2000, Ostrava, Czech Republic, May, Lecture No. 542, p. 45. 